\title{
An ANN and RSM Integrated Approach for Predict the Response in Welding of Dissimilar Metal by Pulsed Nd:YAG Laser
}

\author{
B. R. Moharana*, S. K. Sahoo \\ Department of Mechanical Engineering, National Institute of Technology, Rourkela \\ *Corresponding Author: brmoharana88@yahoo.co.in
}

Copyright (C) 2014 Horizon Research Publishing All rights reserved.

\begin{abstract}
Laser welding is an advance non-traditional and high energy beam welding technique for dissimilar material, which is being increasingly used in industries like automobile, nuclear reactors, aerospace etc. Again it is a very tough task to joining dissimilar materials due to their properties variation. In this present work two dissimilar metals such as copper and AISI 304 stainless steel are taken into consideration. Laser weldings are performed using a pulsed Nd: YAG laser welding machine. Experiments are carried out by taking three process parameters such as laser power, welding speed and pulse duration with three levels each. A statistical design of experiment (DOE) technique i.e. Response Surface Methodology (RSM) is adopted for analysis of maximizing the tensile strength. The back propagation artificial neural network (ANN) technique is used to predict the strength of the welded area. The predicted data are compared with the experimental results and is found to be in agreement.
\end{abstract}

Keywords ANN, Dissimilar Metal, Nd:YAG Laser, RSM, Tensile Strength

\section{Introduction}

Laser welding is a unique welding process which offers non-contact autogenously welding and not affected by the electrical conductivity or magnetic properties of the materials being welded. It is a great challenge to weld two different materials with different mechanical and physical properties. In the recent years the demand of dissimilar metal joint increases due to their wide applications in industries likes automobiles, nuclear reactors, microelectronics, avionics etc. which can provide appropriate mechanical properties and good cost reduction. Mai and Spowage (2004) expressed, this also used in the power generation, chemical, petrochemical, nuclear and electronics industries for the purpose of tailoring component properties or weight reduction.

In this work, two dissimilar metals such as pure copper and AISI 304 stainless steel are considered for joining by pulsed Nd:YAG laser. The welding is successful when the strength of weldment is more than the parent materials. To obtain maximum tensile strength, it is essential to take more attention on the process parameters. So various statistical and prediction techniques are used to optimizing the process parameters. Aggarwal et al. (2008), Asilturk and Neseli (2012) interpreted that the Response surface methodology (RSM) is one of the most efficient statistical optimization technique for both single and multi-response optimization. Sivarao et al. (2010) presented the effect of laser parameters on surface roughness in laser machining through RSM modeling. Rizzi et al. (2011) described that, the penetration depth and the melted area increases as far as the laser power is increased or the welding speed is lowered, the plasma electron temperature decreases. It means the laser power is the most influent parameter on the entire response variable. Zhao et al. (2012) explained the optimal combination of the laser welding input variables to obtain superior weld joint through

RSM modeling. They also described as welding speed had a negative effect on all responses, whereas laser power had positive effect. In this present study, RSM technique is used to optimizing the process parameters to maximize the welding strength.

There are varieties of Artificial Intelligence (AI) methods available includes time series models, regression models, adaptive neuro-fuzzy inference systems (ANFIS), artificial neural network (ANN) etc. have been implemented as major techniques for controlling and monitoring the welding processes. Presently the use of ANN has increased gradually in the field of engineering. As described by Rajkumar and Murugan (2012), it is one of the powerful modeling techniques based on statistical approach, presently practiced in the field of engineering for modeling complex relationships which are difficult to explain with physical models. 
Olabi et al. (2006) optimized in the ranges of the investigated parameters using the $\mathrm{L}_{9}$ Taguchi approach and artificial neural networks and calculate the optimal penetration depth, fused zone width and heat affected zone width. Pal et al. (2007) found that the welding strength predicted by the developed ANN model is better than that based on multiple regression analysis. A multilayer neural network model has been developed to predict the ultimate tensile stress (UTS) of welded plates. Lakshminarayanan and Balasubramanian (2009) compared the tensile strength of friction stir welded AA7039 aluminium alloy joints obtained experimentally with ANN prediction value Sensitivity analysis was carried out to identify critical parameters. Balasubramanian et al. (2010) explained the effect of laser power, welding speed and beam incident angle on the butt weld bead geometry, i.e. depth of penetration (DOP) and bead width (BW) for laser beam welding (LBW) of austenitic stainless steel (AISI 304). They also used the back-propagation trained neural network for modeling and predicting the laser welding of stainless steel butt joint.

The present study is initiated to develop an ANN model to predict the values of tensile strength resulting from a $\mathrm{Nd}$ :YAG laser butt welding process and to evaluate optimum setting by using RSM method.

\section{Research Methodology}

\subsection{Design of Experiment}

Experiments are conducted by the RSM design matrix using central composite design (CCD) with three variables yield a total of 20 runs in three blocks. MINITAB $16^{\circledR}$ is used for this design. This design is based on three process parameters such as welding power, welding speed and pulse duration with three levels each. The process parameters and their levels are shown in Table 1.

Table 1. Process parameters and experimental design levels

\begin{tabular}{|c|c|c|c|c|}
\hline \multirow{2}{*}{ Variables } & \multirow{2}{*}{ Symbols } & \multicolumn{3}{|c|}{ Levels } \\
\cline { 3 - 5 } & & $(-1)$ & $(0)$ & $(1)$ \\
\hline Laser power $(\mathrm{kW})$ & $\mathrm{P}$ & 5.8 & 6 & 6.2 \\
\hline Welding speed(mm/s) & $\mathrm{S}$ & 0.8 & 1 & 1.2 \\
\hline Pulse duration(ms) & $\mathrm{T}_{\mathrm{p}}$ & 14 & 15 & 16 \\
\hline
\end{tabular}

Two dissimilar metals plates such as AISI 304 stainless steel and pure copper are employed for this investigation. The size of each plate is $70 \mathrm{~mm}$ long $\times 20 \mathrm{~mm}$ width with $1 \mathrm{~mm}$ thickness. The specimens are prepared for tensile test as per the American Society for Testing of Materials (ASTM E8M-04) guidelines. EDAX (Energy-dispersive X-ray spectroscopy) has been done to find out the chemical composition of the base metals are given in Tables 2(a) and 2(b).
Table 2(a). Chemical composition of AISI 304 stainless steel (mass fraction, \%)

\begin{tabular}{|c|c|c|c|c|c|c|c|}
\hline $\mathrm{C}$ & $\mathrm{Si}$ & $\mathrm{Cr}$ & $\mathrm{Mn}$ & $\mathrm{Fe}$ & $\mathrm{Ni}$ & $\mathrm{P}$ & $\mathrm{S}$ \\
\hline 0.08 & 1 & 18 & 2 & 70.345 & 8.5 & 0.045 & 0.03 \\
\hline
\end{tabular}

Table 2(b). Chemical composition of pure copper (mass fraction, \%)

\begin{tabular}{|c|c|c|}
\hline $\mathrm{C}$ & $\mathrm{Si}$ & $\mathrm{Cu}$ \\
\hline 3.88 & 0.82 & 95.29 \\
\hline
\end{tabular}

\subsection{Experimental Work}

Two plates of AISI 304 stainless steel and copper are taken into consideration as explained above for the experiments i.e. butt welding. The welding is carried out according to RSM design matrix as shown in Table 3 in a Pulsed Nd:YAG(Alpha 200) laser machine. The experimental set-up is shown in Fig. 1. The specification of the machine is such as: wavelength $1.06 \mu \mathrm{m}$, maximum average power $200 \mathrm{~W}$, peak pulse power $100 \mathrm{~kW}$, pulse energy $90 \mathrm{~J}$, focusing diameter $0.3-2 \mathrm{~mm}$, pulse frequency $20 \mathrm{~Hz}$ and pulse duration $1-20 \mathrm{~ms}$. Argon is used as the shielding gas. After completion of the welding samples are tested for their tensile strength in a universal testing machine (INSTRON) as shown in Fig. 2. The tensile strength in terms of load in kilo newton $(\mathrm{kN})$ values are also listed also in the Table 3 .

Table 3. Experimental design matrix and results

\begin{tabular}{|c|c|c|c|c|c|c|}
\hline \multirow{2}{*}{$\begin{array}{c}\text { Run } \\
\text { No. }\end{array}$} & \multicolumn{2}{|c|}{ Coded value } & \multicolumn{3}{|c|}{ Tensile Load $(\mathrm{kN})$} \\
\cline { 2 - 7 } & $\mathrm{P}$ & $\mathrm{S}$ & $\mathrm{Tp}$ & Experimental & Predicted & \% Error \\
\hline 1 & -1 & -1 & -1 & 17.55 & 17.5503 & -0.0017 \\
\hline 2 & 1 & 1 & -1 & 17.77 & 17.7686 & 0.0079 \\
\hline 3 & 1 & -1 & 1 & 18.15 & 18.1094 & 0.2242 \\
\hline 4 & -1 & 1 & 1 & 17.75 & 17.6433 & 0.4340 \\
\hline 5 & 0 & 0 & 0 & 17.83 & 17.8332 & -0.0179 \\
\hline 6 & 0 & 0 & 0 & 17.82 & 17.8332 & -0.0740 \\
\hline 7 & 1 & -1 & -1 & 17.92 & 18.1713 & -1.3830 \\
\hline 8 & -1 & 1 & -1 & 17.50 & 17.4994 & 0.0034 \\
\hline 9 & -1 & -1 & 1 & 17.70 & 17.7941 & -0.5288 \\
\hline 10 & 1 & 1 & 1 & 18.11 & 17.9641 & 0.8122 \\
\hline 11 & 0 & 0 & 0 & 17.83 & 17.8332 & -0.0179 \\
\hline 12 & 0 & 0 & 0 & 17.85 & 17.8332 & 0.0942 \\
\hline 13 & -1 & 0 & 0 & 17.65 & 17.6773 & -0.1544 \\
\hline 14 & 1 & 0 & 0 & 18.04 & 18.0401 & -0.0006 \\
\hline 15 & 0 & -1 & 0 & 17.85 & 17.8494 & 0.0034 \\
\hline 16 & 0 & 1 & 0 & 17.79 & 17.6686 & 0.6871 \\
\hline 17 & 0 & 0 & -1 & 17.72 & 17.7196 & 0.0023 \\
\hline 18 & 0 & 0 & 1 & 17.96 & 17.9602 & -0.0011 \\
\hline 19 & 0 & 0 & 0 & 17.86 & 17.9585 & -0.5485 \\
\hline 20 & 0 & 0 & 0 & 17.84 & 17.8332 & 0.0381 \\
\hline & & & & & & \\
\hline 19 & & & & \\
\hline
\end{tabular}




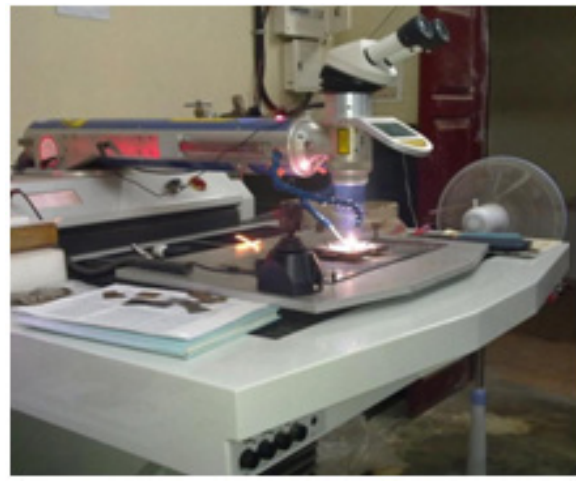

Figure 1. Experimental set-up

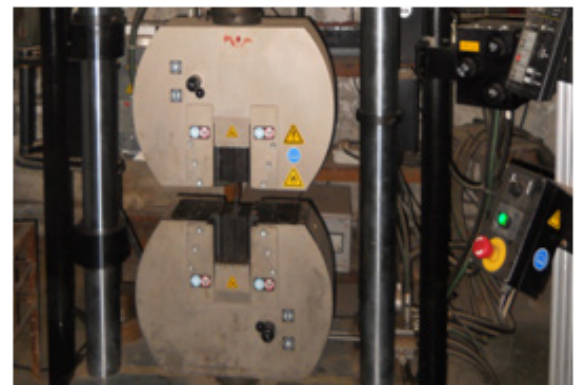

Figure 2. Tensile test of specimen

\subsection{Artificial Neural Network (ANN)}

ANNs are computational models, which replicate the function of a biological network, composed neurons are used to solve complex functions various applications. The ANN used here consists of three layers named as input layer, hidden layer and output layer as shown in Fig.3. The Input layer consists of different number of inputs variables/process parameters as described before. The Back Propagation Algorithm (BPA) is essentially stochastic approximation to nonlinear regression. Several researchers are used BPA to model welding processes and predict welding parameters using neural network.

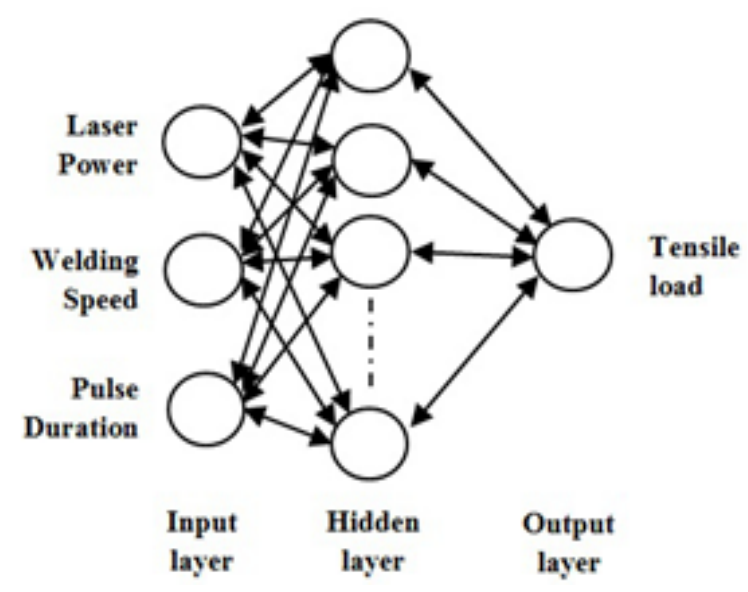

Figure 3. Neural network architecture

In this work, MATLAB 7.6 is used for training the network model for tensile strength prediction. The designed neural networks structure used here is $3-9-1$, with 3 corresponding to the input layer neurons, 9 to hidden layer neurons and 1 to output layer neurons. The numerical optimization technique used for this work is called Levenberg-Marquardt (LM). The architecture of a three layered neural network is shown in Fig. 1.The developed ANN architecture is trained with help of back propagation algorithm using 13 data sets. The neural network described in this work, after successful training, is used to predict the tensile strength of welded joints. The data used for testing are indicated in Table 3 in boldfaced "Run No.". The \% errors listed in Table 3 are calculated between the experimental and predicted value ranging between \pm 1.383 . This result elucidated that, the developed neural network model have high accuracy for the tensile strength prediction.

\section{Results and Discussions}

\subsection{Influences on Response}

During laser welding of two dissimilar metals, the influence of various welding parameter like laser power, pulse duration and welding speed has significant effect on tensile strength, as shown in main effect plot for mean of tensile strength in Fig.4.

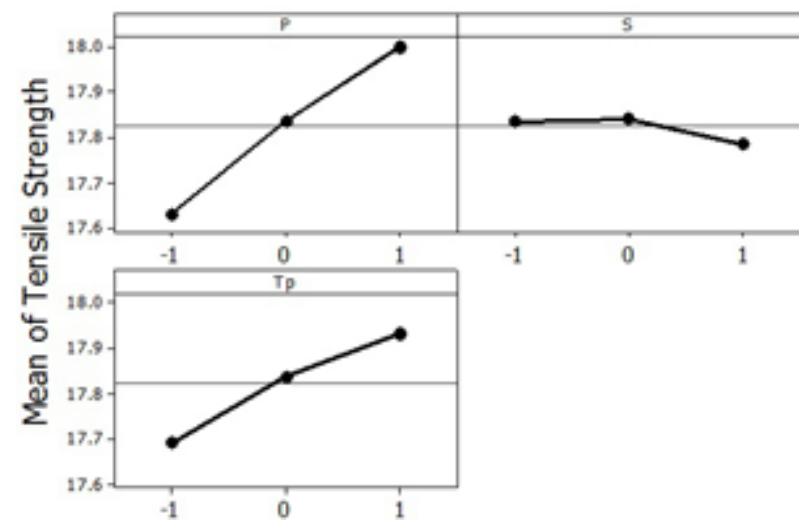

Figure 4. Main effect plot for tensile strength

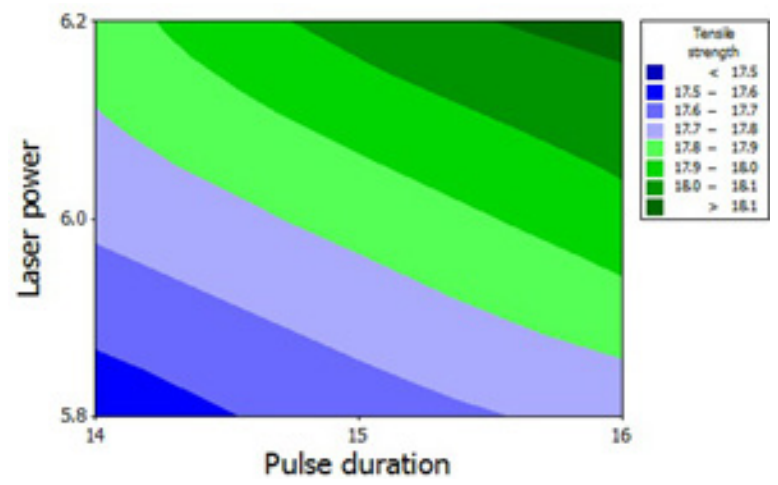

Figure 5(a). Contour Plot of Tensile strength vs $\mathrm{P}$ and $\mathrm{Tp}$

Laser power is directly proportional to the strength means increasing in the laser power from $5.8-6.2 \mathrm{~kW}$ the tensile 
strength is also increasing. When welding speed increases, the weld strength increases slightly at the optimum level and then decreases due to the insufficient time availability for heating the weld zone. Again the pulse duration is also directly proportional to strength. This can be also clear from the contour plot as shown in Figs. 5(a) 5(b).

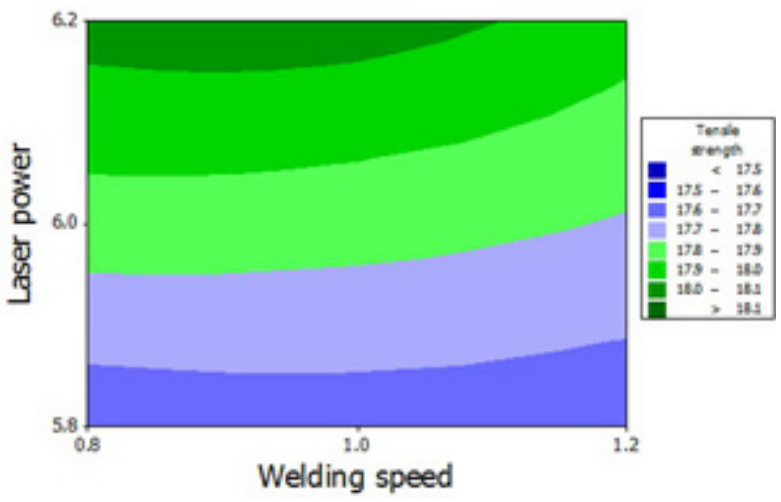

Figure 5(b). Contour Plot of Tensile strength vs $\mathrm{P}$ and $\mathrm{S}$

The residual plot for tensile strength is shown in Fig.6. This residual plot in the graph for normal probability plot indicates the data are normally distributed and variables are influencing the response. And the Residuals versus fitted value indicate the variation is almost constant. According to the histogram, datas are not skewed and not outline exist approximately. Residual versus order of the data indicates that there are systematic effects in the data due to time or data collection order.
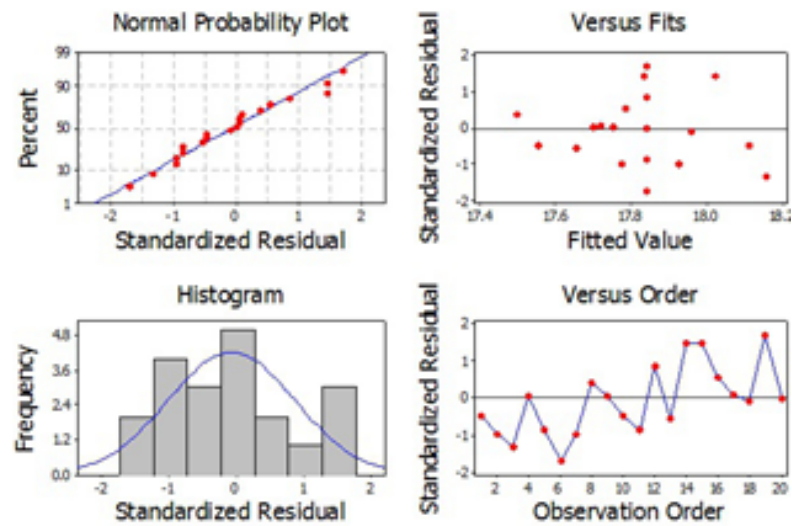

Figure 6. Residual plot of tensile strength

\subsection{Analysis of Variance (ANOVA)}

The purpose of ANOVA is to investigate which welding process parameter significantly effect on the response i.e tensile strength in terms of tensile load. The ANOVA result for the tensile strength is listed in Table 4. The determination coefficient $\left(\mathrm{R}^{2}\right)$ indicates the goodness of fit for the model. In this model, the value of the determination coefficient $\left(\mathrm{R}^{2}=99.81 \%\right)$ indicates that only less than $1 \%$ of the total variations are not explained by the model. The value of adjusted determination coefficient (adjusted $\mathrm{R}^{2}=99.55 \%$ ) is also high, which indicates a very high significance of the model.

Table 4. ANOVA results for tensile strength

\begin{tabular}{|c|c|c|c|c|c|}
\hline Source & DF & SS & Adj. MS & $\mathrm{F}$ & $\mathrm{p}$ \\
\hline Blocks & 2 & 0.002841 & 0.000350 & 2.86 & 0.115 \\
\hline $\mathrm{P}$ & 1 & 0.338560 & 0.338560 & 2772.77 & 0.000 \\
\hline $\mathrm{S}$ & 1 & 0.006250 & 0.006250 & 51.19 & 0.000 \\
\hline $\mathrm{Tp}$ & 1 & 0.146410 & 0.146410 & 1199.08 & 0.000 \\
\hline $\mathrm{P} * \mathrm{P}$ & 1 & 0.000794 & 0.000002 & 0.02 & 0.899 \\
\hline $\mathrm{S}^{*} \mathrm{~S}$ & 1 & 0.001981 & 0.001561 & 12.79 & 0.007 \\
\hline Tp*Tp & 1 & 0.000046 & 0.000046 & 0.37 & 0.558 \\
\hline $\mathrm{P} * \mathrm{~S}$ & 1 & 0.004513 & 0.004513 & 36.96 & 0.000 \\
\hline $\mathrm{P} * \mathrm{Tp}$ & 1 & 0.003612 & 0.003612 & 29.59 & 0.001 \\
\hline $\mathrm{S} * \mathrm{Tp}$ & 1 & 0.005513 & 0.005513 & 45.15 & 0.000 \\
\hline $\begin{array}{l}\text { Residual } \\
\text { Error }\end{array}$ & 8 & 0.000977 & 0.000122 & & \\
\hline Lack-of-Fit & 5 & 0.000527 & 0.000105 & 0.70 & 0.660 \\
\hline Pure Error & 3 & 0.000450 & 0.000150 & & \\
\hline Total & 19 & 0.511495 & & & \\
\hline \multicolumn{2}{|c|}{$\mathrm{S}=0.0110500$} & \multicolumn{2}{|c|}{$\mathrm{R}^{2}=99.81 \%$} & ted $R^{2}=$ & $55 \%$ \\
\hline
\end{tabular}

Again Table 4 shows that all linear and interaction coefficients are significant. From the square coefficients only one i.e. $\mathrm{S} * \mathrm{~S}$ is significant. From all significant coefficients the highest $\mathrm{F}$ value is obtained for $\mathrm{P}$ equal to 2772.77 , means it has highest effect on the response. The F value for the Tp is equal to 1199.08 , which indicates that the $\mathrm{Tp}$ has a relatively lesser effect on the process and similarly the $\mathrm{F}$ value of $\mathrm{Tp}$ and other coefficients are very low indicate that very less effect on the response.

\subsection{Comparison between RSM and ANN}

After successful welding of two dissimilar metals the experimental and predicted tensile strength values are listed in Table 3, according to RSM design matrix and ANN respectively. The comparisons between experimental and predicted values are shown in Fig.7.

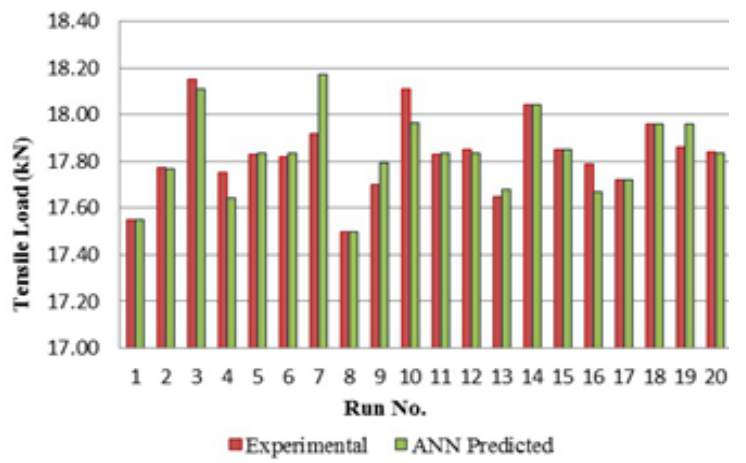

Figure 7. Comparison between values obtained from experiments and ANN prediction 
It is shown from the above figure that the experimental and predicted output values are close to each other. The proposed neural network has the modeling competence with average accordance ratio of almost $98.617 \%$.

\section{Conclusions}

From the above discussion following important conclusions are derived:

1. Laser power has strong influence on tensile strength. By changing the $\mathrm{P}$ value the response will be changed dramatically, so the $\mathrm{P}$ value should be carefully selected.

2. The pulse duration has also strongly affect the strength but less than power. But we cannot ignore this parameter.

3. Experiments validated that the desired high quality welds can be achieved using the optimal parameters obtained by the RSM design.

4. From the comparison it is clear that an artificial neural network is one of the alternate to predict the tensile strength. Hence it can propose for real time work environment.

\section{REFERENCES}

[1] Aggarwal, A., Singh, H., Kumar, P. and Singh, M. (2008) Optimizing power consumption for $\mathrm{CNC}$ turned parts using response surface methodology and Taguchi's technique-A comparative analysis. Journal of materials processing technology, (200), 373-384.

[2] Asilturk, I. and Neseli, S. (2012) Multi response optimization of CNC turning parameters via Taguchi Method-based response surface analysis. Measurement, (45), 785-794.
[3] Balasubramanian, K.R., Buvanashekaran, G. and Sankaranarayanasamy, K. (2010) Modeling of laser beam welding of stainless steel sheet butt joint using neural networks, CIRP Journal of Manufacturing Science and Technology, (3), 80-84.

[4] Lakshminarayanan, A.K. and Balasubramanian, V. (2009) Comparison of RSM with ANN in predicting tensile strength of friction stir welded AA7039 aluminium alloy joints. Trans. Nonferrous Met. Soc. China, (19), 9-18.

[5] Mai, T.A. and Spowage, A.C. (2004) Characterization of dissimilar joints in laser welding of steel-kovar, copper-steel and copper-aluminium. Materials Science and Engineering A, (374), 224-233.

[6] Olabi, A.G., Casalino, G., Benyounis, K.Y. and Hashmi, M.S.J. (2006) An ANN and Taguchi algorithms integrated approach to the optimization of $\mathrm{CO} 2$ laser welding. Advances in Engineering Software, (37), 643-648.

[7] Pal, S., Pal, S.K. and Samantaray, A.K. (2008) Artificial neural network modeling of weld joint strength prediction of a pulsed metal inert gas welding process using arc signals, Journal of materials processing technology, (202), 464-474.

[8] Rajkumar, G.B. and Murugan, N. (2012) Prediction of Weld Bead Geometry using Artificial Neural Networks on 2205 Duplex Stainless Steel. European Journal of Scientific Research, ISSN 1450-216X (78), 85-92.

[9] Rizzi, D., Sibillano, T., Calabrese, P.P., Ancona, A. and Lugara, P.M. (2011) Spectroscopic, energetic and metallographic investigations of the laser lap welding of AISI 304 using the response surface methodology. Optics and Lasers in Engineering, (49), 892-898.

[10] Sivarao, Anand, T.J.S., Ammar and Shukor. (2010) RSM Based Modeling for Surface Roughness Prediction in Laser Machining, International. Journal of Engineering \& Technology, (10), 34-39.

[11] Zhao, Y., Zhang, Y., Hu, W. and Lai, X. (2012) Optimization of laser welding thin-gage galvanized steel via response surface methodology. Optics and Lasers in Engineering, (50), $1267-1273$. 